\title{
The Origin and Evolution of the Pre-Qin Suffering Consciousness Wen-ping MA ${ }^{1, a,{ }^{*},}$ Xian $\mathrm{Li}^{1, b}$
}

${ }^{1}$ Ideological and Political Theory Teaching and Research Faculty, Dalian Jiaotong University,

Dalian, Liaoning, China

a email: wenpingdl@sina.com b email: lixian@djut.edu.cn

${ }^{*}$ Corresponding author

Keywords: Pre-Qin Suffering Consciousness, Divination, Calamity, Weal and woe

\begin{abstract}
Human consciousness has its historical process of its occurrence and development, and every kind of consciousness of human being will evolve with the change of the times, and so did the Pre-Qin suffering consciousness. In the development process of consciousness in Pre-Qin Dynasty history, it experienced three stages with horary consciousness, calamity consciousness, and weal and woe consciousness, eventually developed into mature suffering consciousness form. In this process, it demonstrated the development and growth of the genealogy of consciousness richly and lively.
\end{abstract}

\author{
先秦忧患意识的源起和嬗变 \\ 马文萍 $1, a,{ }^{*}$, 李先 $1, b$, \\ 1 大连交通大学思想政治理论课教学科研部, 大连, 辽宁, 中国 \\ aemail:wenpingdl@sina.com bemail:lixian@djut.edu.cn \\ *通讯作者
}

关键词:先秦忧患意识;卜卦;灾异;福祸

中文摘要: 人类意识有其发生和发展的历史过程, 人类的每一种意识形式都会随着时代变迁而 发生类型演变, 先秦忧患意识也如是。在先秦忧患意识发展史过程中, 大致经历了卜卦意识、 灾异意识和福祸意识等阶段, 最终发育为较为成熟的忧患意识形式, 这一过程当中, 展示出 了古代人们丰富而生动的 “意识谱系” 的发育和成长历程。

\section{1. 引言}

在先秦古籍中 “忧”、“患”之说比比皆是, 并已将 “忧患” 连用。当代新儒家代表徐 复观在其著作《先秦人性论史》中首次提出 “忧患意识” 的概念, 用以指商周之际所萌发出 的心理突破和精神自觉。在徐复观看来, 忧患意识超越了原始宗教动机的恐怖、绝望, 开始 了人类精神上的责任自觉, 并且作为意识发展的一种高级形式, 兴起于西周初年时期 ${ }^{[1]}$ 。由 此可见, 忧患意识作为一种特殊的心理感受和精神气质, 其萌发受到历史时代变迁、人文理 性觉醒和主体意识兴起所影响。 


\section{2. 忧患意识的原始形态：卜卦意识}

从最初的起源上说, 忧患意识一定根源于事物或事件的不确定而产生的恐惧心理, 担心 它们可能造成意外的威胁、伤害或损失。因此, 人们试图通过某种方式以求得对事件预判。 在现代就是所谓的科学预测, 在古代其主要形态就是占卜之术。可以说, 卜卦意识是忧患意 识的原始形态。占卜又可分为卜和筮, 《礼记 - 曲礼上》曰: “龟为卜, 策为筮” 。不仅国 之大事, 许多小事也要筮卜。据殷商、西周时期甲骨卜辞记载, 经常占卜的是疾病、财务、 渔猎、盗贼等事项，也包括明天有没有雨、打仗能不能赢，收成会不会好等等。在根本上， 占卜的用意在于事先获知行为的吉凶, 以便做好趋吉避凶的准备。因此, 不妨将古人的这种 试图借助（下、筮、卦、星相等）符号变化来窥测神明意向的认知模式, 统称为卜卦意识。 卜卦意识作为古人原始质朴的思维方式, 带有明显的神秘主义色彩和比类思维特征。

首先, 按照人类学家列维 - 布留尔的看法, 在原始思维方式和世界观中, 世界具有神秘 性，到处充满了 “灵性”、“神秘的力量的连续” 和 “不间断的生命的本原” ${ }^{[2]}$, 从一草一 木到山川河流, 无不打上神秘意志的印记, 至于纯粹物质的自然界、纯粹物理的现象是根本 不存在的。既然, 世界被看作一个充满情感意志和神秘属性的泛神论的万物有灵的世界, 那 么日常生活发生的普通的事件和现象就与人的吉凶祸福发生了联系, 这一点在《易经》中也 被明显地保留了下来。 ${ }^{[3]}$ 《易传》明确指出, 八卦的产生是为了 “通神明之德”、“类万物 之情” , 是为了 “知幽明之故”、“知死生之说” , 是为了 “行其典礼”、“断其吉凶”, 是为了 “尽意”、“尽利”、“尽神”。

其次，龟卜时代毕竟还没有形成指导生活和实践的较为系统的科学知识，人们只好倚重 于生活的个别经验, 当看到某一现象发生后, 继之而来另一现象, 那么在头脑中就会形成某 种关联联想, 并加以记录。原始思维并非基于线性因果关系或者说决定论因果关系, 去寻求 解释某一现象的原因, 而是比类思维的支配下, 对先后出现的两个不同事物和两种不同现象, 寻求一种关联性。这种神秘主义基础上的 “因果联想” 的认知形式, 成为先秦占卜者和阴阳 家认识和把握世界的基本方式。

\section{3. 灾异意识中 “天谴说” 的主流地位确立}

灾异由 “灾” 和“异”二字组成，“灾”指灾害、灾难，如地震、冰冻、大旱、洪涝、 虫病、瘟疫等; “异” 指怪异、异常, 既包括怪异事件也包括异常现象, 如陨石落地、貖鸟 退飞等怪事或者日月食、不合季节的风霜雨雪寒暑等异常。西周时人语 “国之将兴, 必有祥 祯, 国之将亡, 必有妖莘” 反映的正是这种思想。灾异意识是古人对自然界和人世间的各种 灾异现象的一种认知、理解和评价, 其核心在于 “重异不重灾”。灾异意识与卜卦意识有相 通之处, 也有不同之处, 相通之处即都是灵性世界观和原始思维形态的表现, 都包含着对人 世吉凶的预测和判断。不同之处在于，区别于占卜工具和手段，灾异更注重对自然事物或现 象的异样变化的观察, 以推断人世的吉凶, 而且往往关乎统治阶级的政权稳定, 因而灾异发 生，统治者多会从中得出警示、反思和补过。

古代灾异意识具有多种理论形态, 主要由灾异天谴说、时令失序说和鬼神作宗说等形式。 对灾异解释的说法各异，反映了古代灾异思想的不同争议。时令失序的观念代表着中国古代 少数 “精英” 的思想, 包含较多的哲学成分, 其社会影响也相对较小; 鬼神作崇说构成了民 间宗教方术的理论基础, 融入到伦常日用的习俗之中; 天谴说则与君权专制形态相结合获得 了上层统治承认，成为官方传统、士人传统和民间传统普遍认可和接受的灾害知识与思想， 一直占据着古代灾异解释的绝对主流，构成了古代官方的灾害意识形态。

天谴说强调 “天下利害出于一人”, 这种灾异理论在西汉得以系统化、神秘化和政治化, 其实折射了秦汉之后君王权力的上升和文人士大夫地位的下降的双向流动。秦汉帝国相继建 立, 形成以皇帝为中心的君主专制的统治。所谓 “三代以上, 藏天下于天下; 三代以下, 藏 
天下于筐筐”，除了王位继承是 “家天下” 外，连天下也当作自家的私有财产，君主权力至 高无上, 喜怒无常, 草菅人命。相反, 士人阶层从原来的王者之师降为帝家之臣, 丧失了 “见 大人则藐之” 的文化优越感和对帝王过失的道统批判力。因此, 董仲舒等士人通过 “屈君伸 天”，借助灾异现象委婉地批评帝王德行失检施政不当，从而以达到对君主的监督、训诫、 谴责和纠偏, 这也是不得已之为。但是这种做法毕竟屈从于帝王淫威, 以致后来灾异天谴说 与谶纬说相结合, 重异不重灾, 越来越失去了批判警示功能而走向预言化, 反而变成了有意 强调君主统治的合理性、神化君主权威的工具, 而君主也乐得披着神学的神圣外衣巩固其世 俗权力。

\section{4. 趋吉求福的福祸（吉凶）意识}

何谓吉凶福祸？《周礼・春官・大祝》曾经说到，大祝要负责 “六祝”，即 “顺丰年”、 “求永贞”、“祈福祥”、“弭灾兵”、“逆时雨宁风旱”、“远罪疾”，这些内容就是人 们心中最基本的吉凶福祸。吉凶福祸所主要涉及个体生存所必需的各个基本层面。《礼记・祭 统》指出: “福者, 备也。备者, 百顺之名也, 无所不顺谓之备。” 《韩非子 - 解老篇》也 谓：“全寿富贵之谓福。”古人也有用 “大恶” 表示凶祸意思，如《礼记・礼运》曰： “饮 食男女, 人之大欲存焉。死亡贫苦, 人之大恶存焉。” 《太平经合校》云： “大恶有四，兵， 病, 水, 火”。《吕氏春秋》中《人间》篇还具体谈到了人间祸福吉凶的由来与征兆以及趋 吉避凶的方法。福祸 (吉凶) 意识是价值观念的外在具体表现, 吉、福是人之所欲求，凶、 祸是人之所厌恶，人们总是趋吉避凶、求福躲祸，这当中蕴含着浓厚的忧患意识。

谁是吉凶祸福的主宰者? 在先秦大只可以分为天、命、道、人为吉凶祸福主宰几种主要 观念，并在祸福观上也有 “听天”、“由命”、“顺道”、“人定”之流变。

\section{1 天主祸福}

殷商在统一了中原大部分领土之后，统治者提出了“有命在天”的观念。“天命玄鸟， 降而生商, 宅殷土芒芒。古帝命武汤, 正域彼四方”（《诗经・玄鸟》）。为了禳天弭灾, 和天上神祇沟通, 就必须有天人或神人之间的媒介, “在男曰爽, 在女曰巫” (《国语. 楚语 下》），如商代的卜人、周代的巫、韾或史，他们有 “通天” “降神” 的法力从而可以打通 神人世界。

虽然在后世，以天为最高的神灵和万物的主宰的思想并不断绝，如董仲舒的“天者，百 神之大君也” (《春秋繁露・郊语》) , 但是《国语》中明确宣告了 “绝地天通” : 天地相 分，人神不扰，各得其序天，自此，天之内涵已经发生了根本改变。“天主祸福”，除了在 维系君主统治合法性的意识形态上还依然顽固地保持之外, 随着主宰之 “天” 的解体而消褪, 一种更加抽象、更加神秘的 “命主祸福” 观念随之兴起。

\section{2 命主祸福}

春秋之际的士阶层观念中，天命的“天”的人格性色彩渐渐褪去，单以“命” 来指称主 宰人世的神秘东西, 并进一步引申出人的 “命运”、“寿命”、“生命” 等概念。当人们意 识到人世许多事情如生死、苦乐、福祸常常非人力所能决定和左右之时, 自然会产生不无神 秘的 “宿命” 意识, 因此, 时人常有 “死生有命, 富贵在天”（《论语 - 颜渊》）的感慨。

先秦思想家中，孔子和后世儒者都主张有命，道家老庄也同样讲命，甚至比儒家更为极 端。墨子则反对命说而倡 “非命”，墨子去世后非命说影响也随之式微。“命”之所以自先 秦以来一直成为重要思想范畴, 恰恰表明了人世的复杂和论谲, “命” 乃是对生存不确定性 寻求思想的确定性解释，是种种生存忧患意识在观念上的映像和折射。 


\section{3 道主福祸}

随着思想理性化的不断展开, 先秦诸子大多已经不再相信 “天”是 “人格化神”了。“道” 成了取代 “天” 的新的弥漫于宇宙之间的超越力量。道的本义为路, 后引申事物存在和变化 的过程、规律, 并进一步抬高到宇宙的最高实体、世界本原。道有天道 (与之相应还分为地 道）和人道之分。

春秋前, “道” 的观念大体是指 “天道”, 此时还没有完全脱离原始宗教的阶段, 《国 语》记载单襄公回答鲁成公之问曰: “吾非韾、史, 焉知天道? ” (《国语・周语 (下)》), 韾是乐太师, 掌音乐, 听军声以察吉凶; 史是太史, 掌天时。天道具有人间性, 即可以安排 人间秩序，春秋时晋国乐师师旷说：“天生民而立君，使司牧之，勿使失性。有君而为之氠， 使师保之，勿使过度。”（《左传》襄公十四年）如此一来，天道就能够主宰人世的吉凶祸 福，天道 “盈而荡”（《左传》庄公四年）或者 “盈必毁”（《左传》哀公十一年），吉凶 祸福由此变化生成。

西周特别是春秋之后，随着“人文的觉醒”和 “哲学的突破”之后，整个思想界主流发 生了从言天道向重人道集体转向。即使像道家虽然强调天道, 但是庄子也有《人间世》、《应 帝王》等关注人世和人事之作。《左传》昭公十八年记载: 郑国裨灶根据天文现象的变异预 言将有火灾, 子产批评裨灶说: “天道远, 人道迩。非所及也, 何以知之? (裨) 灶焉知天 道? ”裨灶是郑国薣、史之类的人物, 职业是所谓 “知天道”。现在子产不仅不相信他能够 “知天道” ，更是反对根据天道 (天文现象的变化) 来预言认识祸福的做法。无论是安排和 维持人间秩序, 还是避祸趋福、逢凶化吉, 其责任都根源在于人。自此, 从道主祸福, 也就 顺利地转向人主祸福或者德主祸福的观念。

\section{4 人主福祸}

周人有鉴于夏、殷的灭亡，认为 “天命靡常”，应该从自身的行动中寻找朝代更替的因 果性, 这样就寻找到了 “德”。周人认为, “皇天无亲, 惟德是辅; 自天所佑, 归于有德”, 只有 “敬德” 才能受命保命，只有 “敬德保民”，才能 “祈天永命” ，因为 “天亦哀于四方 之民”。这样就把 “尊天”与 “敬德” 联系起来, 使 “天命” 有了人世的道德义蕴。如此, 人主祸福的观念开始流行起来, 《尚书》云: “天作莘, 犹可活; 自作蒘, 不可活。”人主 福祸的观念也影响着后世的报应观, 得到 “福报” 是善事积累的结果, 得到 “恶报” 则是恶 事积累的结果。如《周易》: “积善之家, 必有余庆; 积不善之家, 必有余殊。”报应观念 在一定程度上也加强了人们对自身行为的约束和控制, 突出了人的主体地位和作用。

\section{5. 忧患意识之发轫}

卜卦意识、灾异意识和福祸意识, 它们共同作为古代意识发展的诸种形式, 呈现出丰富 而复杂的意识发展的历程, 共同编织出一帧忧患 “意识谱系” , 在相互交融和影响过程中, 酝酿出高级意识形态的忧患意识。同时, 忧患意识作为后发的高级意识, 在历史和社会变迁 中, 也在不断地变化和趋于成熟。

同时，还需指出，对于古代先秦意识思想的历史进程，不仅有官方的意识形态思想，也 有知识精英的典籍思想，在普通的民众中还存在着 “一般的知识、思想与信仰” ，它们对人 们判断、解释、处理面前世界共同地起着作用。西周以降, 由于社会结构和阶层分化, 出现 了三大文化传统：官方传统、士人传统和民间传统，它们也可视为政治传统、哲学传统和民 俗传统, 三者之间发生着相互作用的联系和影响。卜卦意识原本作为商周以来官方传统的意 识形式, 卜筮问占在商周地位很高, 后来则渐渐下降为了民间传统, 官方则借助天命观念和 阴阳五行学说, 又发展出新的传统即灾异意识传统。祸福意识作为一般的价值观念, 植根于 中国文化传统中注重现世生活, 重视感官形态, 关注当下生存, 后来又与道教相结合, 是官 方和民间基本相通的观念传统。 
首先, 在世界秩序上, 忧患意识正是在卜卦意识、灾异意识和祸福意识的基础上, 由万 物有灵的神秘主义发展到天命观念再到天人秩序观念逐渐发育。卜卦意识源自于远古以来的 万物有灵思想, 乃是对鬼神神秘力量的畏惧和膜拜，主体理性远未成熟。到了殷商后期，万 物有灵进一步抽象化, 形成了天命观念, 人们心目中神秘力量逐渐秩序化并开始与王权结合 而不断地政教化。到了西周，随着天命观的变化、神权观念的演化以及礼仪制度和宗法制度 的变化, 天人秩序得以进一步合理化, 在这过程当中体现了古人对世界秩序的向往和追求。

其次，在主体性上，卜卦意识、灾异意识和祸福意识的主体性逐渐增强，殷商时期充满 卜辞祭祀的 “尚鬼” 意识, 随着主体性和理性的凸显, 人们不再轻易将吉凶祸福成败托付给 上帝、鬼神以及其它神秘事物, 意味着 “人文精神的觉醒” 并直接酝酿着后来的 “哲学的突 破”。忧患意识不同于作为原始宗教动机的恐怖、绝望, “忧患与恐怖、绝望的最大不同之 点, 在于忧患心理的形成, 乃是从当事者对吉凶成败的深思熟虑而来的远见; 在这种远见中, 主要发现了吉凶成败与当事者行为的密切关系，及当事者在行为上所应负的责任。忧患正是 由这种责任感生发的要以己力突破困难而尚未突破时的心理状态。所以忧患意识, 乃人类精 神开始直接对事物发生责任感的表现，也即是 “精神开始有了人地自觉表现。” ${ }^{[5]}$ 忧患意识 之所以是从 “人之自觉” 中产生的, 是因为在以信仰为中心的宗教气氛之下, 人感到由信仰 而得救, 把一切问题的责任交给神, 在这种情形之下不会产生忧患意识。只有自己担当起责 任时, 才会有忧患意识。因此, 忧患意识要比卜卦意识、灾异意识和宿命论下的祸福意识更 强调主体性和责任感, 因此在意识形式要更为高级。

再次，从意识形式的产生上说，卜卦意识、灾异意识和祸福意识都关注 “人之在世”问 题, 人如何生活于宇宙之中? 又如何与世间万物交道? 只有在充分地认识和体会到生存艰辛 和世事艰难, 特别产生凶、险、祸、难等担忧、思虑和戒惧, 才会产生自觉的危机感、紧迫 感、责任感, 也才会激发出强烈的忧患意识, 说到底, 忧患意识区别于卜卦意识、灾异意识 和一般大众的祸福意识等较为朴素的意识形式, 无论是在心理结构还是思维方式上, 都更为 深刻和丰富, 代表着高级的忧患精神文化发展形态。因此, 作为晚出和高级的意识形态, 忧 患意识在卜卦意识、灾异意识和祸福意识的促进和酝酿之中喷薄而出。

\section{致谢}

本文为2015年辽宁省社科基金项目《先秦忧患意识的道德基因本质及其当代价值研究》 (L15BZX002) 、大连交通大学党建研究重点课题《提高中国化的马克思主义文化软实力的 哲学研究》(DJSZ-2015-A05)的阶段性成果之一。

\section{References}

[1] [5] Xu Fuguan, The history of human nature in China - Pre Qin, Shanghai Sanlian Bookstore, pp.18-19, 2001

[2] (France) Levi Bruhl, Original Thinking, Beijing University Press, pp.97,1981

[3] Feng Youlan, The history of Chinese philosophy, Zhonghua Book Company, pp.457,1961

[4] Zhang Shuguang, Life philosophy, Yunnan people press, pp.190-191, 2001 